\title{
PRODUÇÃO DE BIOMASSA E AVALIAÇÃO BROMATOLÓGICA DE CULTIVARES DE CAPIM ELEFANTE PENNISETUM PURPUREUM SCHUM. NO PERÍODO OUTONO INVERNO
}

\author{
ARBOITTE, Miguelangelo Ziegler ${ }^{1}$ \\ RIBEIRO, Wagner Bianchin ${ }^{2}$ \\ BOSS, Luca $^{3}$
}

RESUMO: Objetivou-se avaliar a produção de biomassa e a composição bromatológica de três cultivares de Pennisetum purpureum Schum.: Cameron, Carajás e BRS Kurumi. O delineamento experimental foi de blocos ao acaso com três repetições. O Cameron apresentou produção de 7.024,92 $\mathrm{kg}^{\text {.ha }}{ }^{-1}$ de biomassa verde $(\mathrm{P}<0,05)$ em relação aos 5.051,92 e 6.379,00 kg.ha ${ }^{-1}$ do Carajás e do BRS Kurumi. A produção de biomassa seca (BMS), foi superior $(\mathrm{P}<0,05)$ para o Cameron e BRS Kurumi $\left(746,35\right.$ e 638,34 kg.ha $\left.{ }^{-1}\right)$, comparando ao Carajás $\left(514,01\right.$ kg.ha $\left.{ }^{-1}\right)$. A proteína bruta foi maior $(\mathrm{P}<0,05)$ no Carajás $\left(0,225 \mathrm{~kg} \cdot \mathrm{kg}^{-1} \mathrm{BMS}\right)$ em relação aos $0,190 \mathrm{~kg}_{\mathrm{kg}} \mathrm{kg}^{-1} \mathrm{BM}$ do Cameron, já os $0,215 \mathrm{~kg} \cdot \mathrm{kg}^{-1} \mathrm{BMS}$ do BRS Kurumi foi semelhante. A fibra digestível neutra no Cameron e no BRS Kurumi foram semelhantes $(\mathrm{P}>0,05)\left(0,566\right.$ e $0,530 \mathrm{~kg}$ de $\left.\mathrm{FDN} \cdot \mathrm{kg}^{-1} \mathrm{BMS}\right)$ e superior aos $0,457 \mathrm{~kg}$ do Carajás. Os nutrientes digestíveis totais verificados no Carajás foram de $0,647 \mathrm{~kg}$ de NDT. $\mathrm{kg}^{-1} \mathrm{BMS}$, superior aos 0,607 e $0,617 \mathrm{~kg}$ do Cameron e BRS Kurumi. Os cultivares apresentaram semelhança para a fibra digestível ácida, cálcio, fósforo, cobre, ferro e zinco, já o magnésio e o potássio foram menores no BRS Kurumi. O estudo mostrou a viabilidade da utilização dos cultivares no período crítico para a alimentação de ruminantes.

Palavras-chave: BRS Kurumi. Cameron. Carajas. Minerais. Produtividade.

\section{BIOMASS PRODUCTION AND BROMATOLOGICAL EVALUATION OF ELEPHANTGRASS CULTIVARS Pennisetum Purpureum SCHUM. IN THE AUTUMN WINTER PERIOD}

\begin{abstract}
SUMMARY: The objective of this study was to evaluate the biomass production and the bromatological composition of three cultivars of Pennisetum purpureum Schum.: Cameron, Carajás and BRS Kurumi. The experimental design was a randomized complete block design with three replicates. Cameron presented a production of 7,024.92 kg.ha- ${ }^{-1}$ of green biomass $(\mathrm{P}<0.05)$ in relation to the $5,051.92$ and $6,379.00 \mathrm{~kg}^{-h a^{-1}}$ of Carajás and BRS Kurumi. The dry biomass production (BMS) was higher $(\mathrm{P}<0.05)$ for Cameron and BRS Kurumi $(746.35$ and 638.34 kg.ha $\left.{ }^{-1}\right)$, compared to Carajás $\left(514.01 \mathrm{~kg} \cdot \mathrm{ha}^{-1}\right)$. The crude protein was higher $(\mathrm{P}<0.05)$ in the Carajás $\left(0.225 \mathrm{~kg} \cdot \mathrm{kg}^{-}\right.$ ${ }^{1}$ BMS) in relation to Cameron 0,190 kg. $\mathrm{kg}^{-1} \mathrm{BMS}$, whereas the BRS Kurumi $0.215 \mathrm{~kg} \cdot \mathrm{kg}^{-1} \mathrm{BMS}$ was similar. The neutral digestible fiber in Cameron and BRS Kurumi were similar ( $\mathrm{P}>0.05)\left(0.566\right.$ and $0.530 \mathrm{~kg}$ of NDF.kg $\left.{ }^{-1} \mathrm{BMS}\right)$ and higher than the $0.457 \mathrm{~kg}$ of Carajás. The total digestible nutrients found in Carajás were $0.647 \mathrm{~kg}$ of DNT.kg1BMS, higher than 0.607 and $0.617 \mathrm{~kg}$ of Cameron and BRS Kurumi. The cultivars showed similarity to the acid detergent fiber, calcium, phosphorus, copper, iron and zinc, whereas magnesium and potassium were lower in BRS Kurumi. The study showed the feasibility of using the cultivars in the critical period for feeding ruminants.
\end{abstract}

Keywords: BRS Kurumi. Cameron. Carajás. Minerals. Productivity

\footnotetext{
${ }^{1}$ Prof. Dr. Zootecnia - Instituto Federal Catarinense Campus Santa Rosa do Sul

${ }^{2}$ Engenheiro Agrônomo - Instituto Federal Catarinense - Campus Santa Rosa do Sul

${ }^{3}$ Aluno do Curso de Engenharia Agronômica do IFC Campus Santa Rosa do Sul - Bolsista IFC - Instituto Federal Catarinense Campus Santa Rosa do Sul
} 


\section{INTRODUÇÃO}

O Brasil possui aproximadamente 160 milhões de hectares destinadas a pastagens implantadas, naturais e em degradação, esta última representando $6 \%$ das áreas destinadas as pastagens (IBGE, 2019). Além disso, possui o maior rebanho comercial do mundo com 214,69 milhões de cabeça, sendo que no ano de 2018 tornou-se o maior exportador de carne bovina (ABIEC, 2019), quanto a produção leiteira, atualmente é o quinto maior produtor do mundo, com produção estimada de 34,9 milhões de toneladas, para 2017, com acréscimo estimado de 1,0\% em relação ao ano anterior (CONAB, 2017).

As pastagens são o principal recurso alimentar utilizado para os animais ruminantes nos diferentes sistemas de produção animal no Brasil (DALFOVO et al., 2011), existindo no território brasileiro inúmeras espécies nativas com potencial alimentar a serem exploradas, além das espécies forrageiras introduzidas e melhoradas que possuem em muitos casos produtividade e qualidade pouco superior as nativas, se adaptando bem as mais diversas regiões, clima e solo. $\mathrm{O}$ litoral sul catarinense apresenta privilégios quanto a sua localização geográfica, o clima é temperado com poucas ocorrências de geadas, a precipitação é bem distribuída em razão da sua proximidade com o mar e a Serra Geral, permitindo a utilização de pastagens compostas por espécies de forragens tropicais e subtropicais, sendo uma região propicia a utilização de sistemas de produção animal baseada em pastagens.

O uso de sistemas a base de pasto para alimentar os bovinos, pode ser considerado economicamente viável, desde que o produtor tenha atenção a fatores como a exigência nutricional da categoria animal trabalhada, determinando em que estágio a planta apresentará melhor disponibilidade e qualidade, sem que haja prejuízos a planta escolhida, e maximizando o desempenho produtivo dos bovinos, seja para a produção de carne ou leite.

Quando a forrageira apresenta todos os atributos para nutrir o animal, como níveis adequados de proteína, energia e minerais, fornecendo a fibra necessária para que ocorra ruminação adequada, essa pode ser a principal fonte alimentar, sendo que em algumas ocasiões pode ser utilizado produtos oriundos da agroindústria para complementar a dieta.

Grande problema nas áreas destinadas a produção de bovinos a pasto, é que as áreas destinadas a esses se encontram em muitos casos em solos de baixa fertilidade natural ou em áreas degradadas, causando problemas nutricionais as plantas e impedindo o máximo vigor produtivo da forrageira, consequentemente afetando a produtividade da pecuária local.

Entre as gramíneas [ Poaceae ] usadas em pastagens para a alimentação de bovinos, destaca-se cultivares do capim elefante [ Pennisetum purpureum (Schum.) ], pelo alto potencial de produção de biomassa verde, valor nutritivo adequado as exigências de animais de produção e 
facilidade de adaptação às condições climáticas predominantes em todo o Brasil. Entretanto, alguns problemas associados com o manejo dessa espécie têm dificultado sua adoção por produtores e a ampliação do cultivo, principalmente na dificuldade de manter estrutura adequada de vegetação devido ao rápido alongamento e lignificação do colmo, que resulta em diminuição da relação folha/colmo, da eficiência do pastejo e do valor nutricional da forragem (CARVALHO et al., 2000).

Tais características de alto potencial produtivo de massa forrageira, qualidade nutricional, palatabilidade, vigor de rebrote e persistência (MARANHÃO et al., 2018 b; VIANA, et al., 2018), adaptação a diferentes condições edafoclimáticas fazem com que o capim elefante seja difundido em regiões tropicais e subtropicais, podendo ser manejado para diferentes finalidades pastejo ou corte (MARANHÃO et al., 2018a), tornando a cultura interessante para o desenvolvimento da pecuária de carne e leite.

O trabalho tem como objetivos avaliar a produção da biomassa vegetal e a composição bromatológica de cultivares de Pennisetum purpureum Schum. cv. Cameron, cv. Carajás e cv. BRS Kurumi, no período de outono/inverno.

\section{MATERIAL E MÉTODO}

O experimento foi realizado nas coordenadas: latitude $29^{\circ} 10^{\prime} 49^{\prime \prime}$ Sul e longitude: $49^{\circ} 49^{\prime}$ 95" Oeste, a uma altitude de 9 metros acima do nível do mar. O solo onde foi implantado o experimento é classificado como Neossolo quartzarênico (EMBRAPA, 2013), o clima do local é do tipo subtropical úmido com temperatura média de $19,2^{\circ} \mathrm{C}$ e precipitação pluviométrica média de $1.600 \mathrm{~mm}$ por ano (INMET, 2016). O experimento foi conduzido no período de abril a agosto de 2017. A ocorrência de precipitação e da temperatura durante o experimento foi conforme o Figura 1 e 2 abaixo, elaborados de dados disponibilizados pelo CIRAM (2017).

Figura 1 - Precipitação ocorrida durante os meses de maio a agosto de 2017.

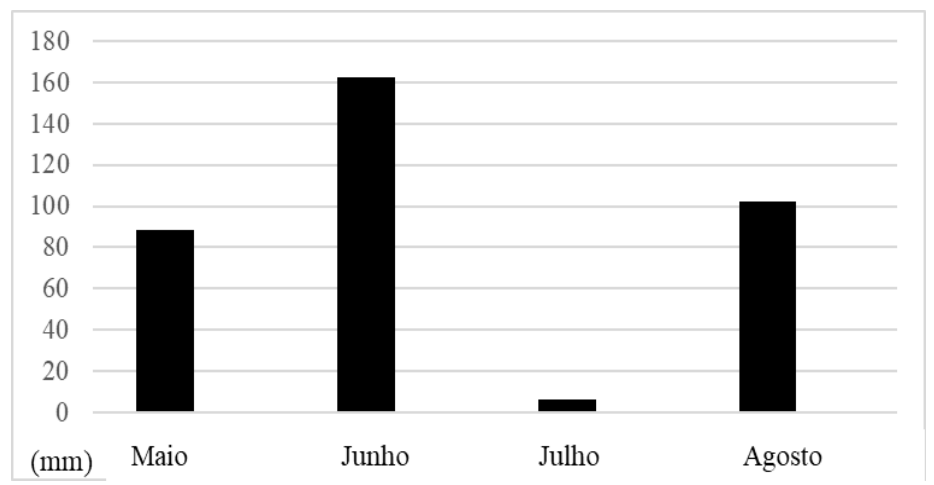

Fonte: CIRAN, 2017 
Figura 2 - Temperatura média do ar nos meses de novembro a setembro.

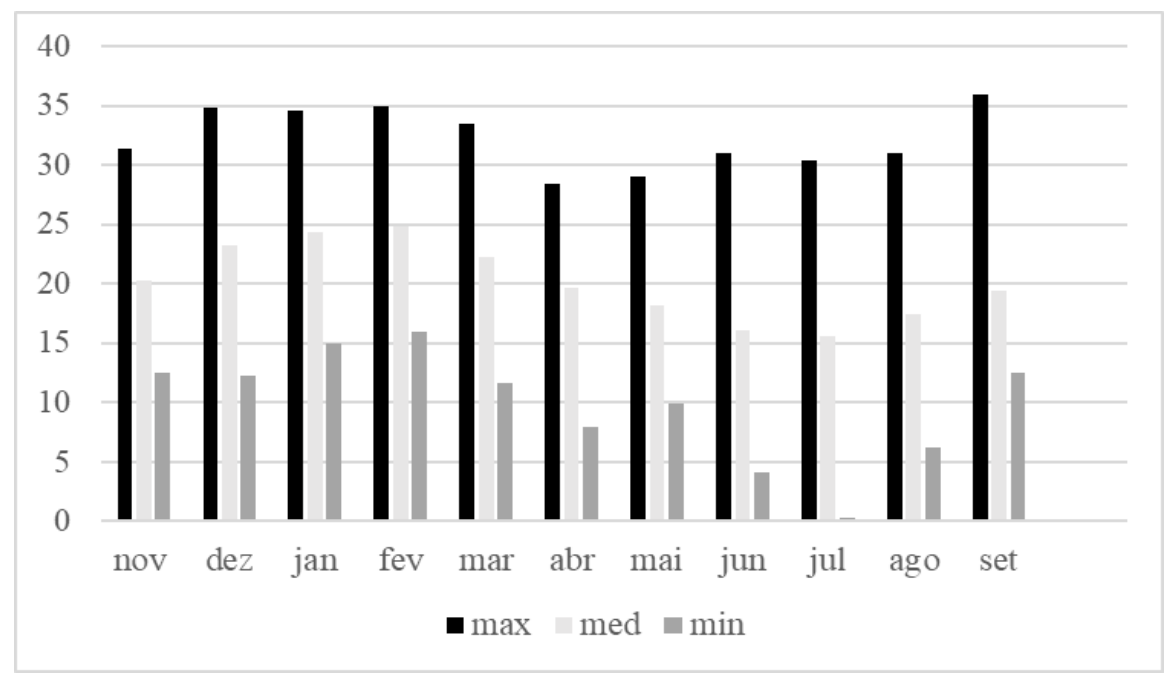

Fonte: CIRAN, 2017

O delineamento experimental utilizado foi o de blocos ao acaso, com três repetições de cada cultivar estudado. Os tratamentos foram as cultivares de Pennisetum purpureum Schum. cv. Cameron, Pennisetum purpureum Schum. cv. BRS Kurumi, Pennisetum purpureum Schum.cv. Carajás. As parcelas apresentavam dimensões de $6 \mathrm{~m}$ de comprimento por $5 \mathrm{~m}$ de largura, com espaçamento entre plantas de $0,85 \mathrm{~m}$ e entre linhas de $1 \mathrm{~m}$.

A área experimental possui histórico de cultivo de tabaco (Nicotiana tabacum L.). Anteriormente a introdução das cultivares de Pennisetum purpureum Schum. foi implantada na área as culturas consorciadas de aveia branca (Avena sativa L.) e azevém (Lolium multiflorum L.), para pastejo de bovinos de leite e cobertura de solo.

No preparo do solo foi realizado uma aração seguida de gradagem, no mês de novembro de 2016, onde foram delimitadas as parcelas experimentais em que forma colocados calcário na dosagem de 3 toneladas $h^{-1}$. Em uma área ao lado também com o solo corrigido foi semeado 0,216 kg de sementes do capim elefante Carajás (Pennisetum purpureum Schum. x Pennisetum glaucum L.). Em janeiro as mudas do capim elefante Carajás foram transplantadas para a área experimental, onde foram implantadas também as mudas de capim elefante cultivar Camerom (Pennisetum purpureum Schum. cv. Cameron) e cultivar BRS Kurumi (Pennisetum purpureum Schum. cv. BRS Kurumi) com adubação de base de 185 kg.ha-1.

Para padronização das cultivares, esses foram cortados a uma altura de $50 \mathrm{~cm}$ do solo após 120 dias da introdução, após formam realizadas coletas aos 30, 60, 90 e 120 dias, que corresponde aos meses de maio, junho, julho e agosto, com o auxílio de um quadro de madeira com dimensões de $1 \mathrm{~m}^{2}$. Após cada corte foi realizada adubação nitrogenadas em cobertura na quantidade de $20 \mathrm{~kg} \cdot \mathrm{ha}^{-1}$ de $\mathrm{N}$. 
As amostras depois de coletadas foram separadas em caule e folhas e essas foram identificadas e pesadas para a determinação da produção de biomassa verde (BMV), em seguida foram encaminhadas para determinação da biomassa seca (BMS), onde primeiramente uma fração amostral foi pesada e seca em estufa de ar forçado a $55-65^{\circ} \mathrm{C}$ por 72 horas, e posteriormente triturada em moinho tipo willey com peneira para granulometria de $1 \mathrm{~mm}$, pesada, colocada em estufa a temperatura de $120^{\circ} \mathrm{C}$ por três horas. A proteína bruta foi determinada conforme Silva e Queiroz (2006). A fibra digestível em detergente neutro e a fibra em detergente ácido foram determinadas de acordo com os procedimentos citados por Senger et al. (2008). A concentração de nutrientes digestível totais (NDT) foi estimada conforme a equação proposta por Capelle et al. (2001) para forragens verdes. A análise para determinação do conteúdo de minerais presentes nas cultivares foi de acordo com os métodos descritos por Malavolta et al. (1997).

Os dados obtidos foram submetidos a análise de variância pelo programa estatístico SISVAR 5.6 e as médias comparadas pelo teste de Tukey a 5\%.

\section{RESULTADO E DISCUSSÃO}

Foram testadas as interações entre cultivares e períodos, não ocorrendo a interação significativa, sendo os períodos retirados do modelo.

Na tabela 1 estão descritos a produção de Biomassa Verde (BMV) produzido pelas cultivares durante o período outono/inverno. É observado que a cultivar Cameron apresentou produção de BMV 7.024,92 kg/ha ${ }^{-1}$, semelhante $(\mathrm{P}>0,05)$ aos $6.379,00 \mathrm{~kg} / \mathrm{ha}^{-1}$ da cultivar BRS Kurumi. Já a produção de BMV da cultivar Carajás verificada foi de $5.051,92 \mathrm{~kg} / \mathrm{ha}^{-1}$, semelhante $(\mathrm{P}>0,05)$ a cultivar BRS Kurumi, mas inferior $(\mathrm{P}<0,05)$ a cultivar Cameron. Em seu trabalho Maranhão et al. (2018b) verificaram que a produção de biomassa verde é influenciada pela precipitação, verificando na época das chuvas a produção estimada em trinta dias de corte pela equação proposta de $4.130 \mathrm{~kg} / \mathrm{ha}^{-1}$, aquém da verificada com os cultivares estudados no presente experimento.

Tabela 1 - Produção, em kg.ha ${ }^{-1}$ de Biomassa Verde (BMV, kg.ha $\left.{ }^{-1}\right)$, Biomassa Seca (BMS, $\mathrm{kg} \cdot \mathrm{ha}^{-1}$ ) e de Proteína Bruta. $\mathrm{kg}^{-1}$ de BMS (PB. $\mathrm{kg}^{-1}$ BMS)nas folhas de Pennisetum purpureum Schum. das cultivares Carajás, Cameron e BRS Kurumi durante o período outono/inverno.

\begin{tabular}{cccc}
\hline Cultivar & BMV, $\boldsymbol{k g} \cdot \boldsymbol{h} \boldsymbol{a}^{-1}$ & BMS, $\boldsymbol{k g} \cdot \boldsymbol{h} \boldsymbol{a}^{-1}$ & PB.kg $^{-1} \mathbf{B M S}$ \\
\hline Carajás & $5.051,92^{\mathrm{b}}$ & $514,01^{\mathrm{b}}$ & $0,225^{\mathrm{a}}$ \\
Cameron & $7.024,92^{\mathrm{a}}$ & $746,35^{\mathrm{a}}$ & $0,190^{\mathrm{b}}$ \\
BRS Kurumi & $6.379,00^{\mathrm{ab}}$ & $683,74^{\mathrm{a}}$ & $0,215^{\mathrm{ab}}$ \\
\hline
\end{tabular}

Letras iguais nas colunas não diferem entre si pelo teste de Tukey a 5\%

Nucleus Animalium, v.11, n.2, nov. 2019 
Ao passar pelo processo de retida de água para estimar a produção de biomassa seca (BMS) durante o período outono/inverno as cultivares Cameron e BRS Kurumi apresentaram

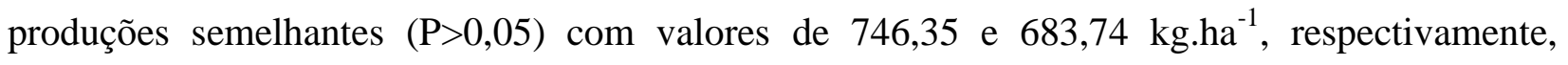
enquanto que a cultivar Carajás a produção foi inferior $(\mathrm{P}<0,05)$ com valor verificado de 514,01 kg.ha ${ }^{-1}$ de BMS.

Entre os fatores ambientais que mais influenciam no acumulo de biomassa verde e no rendimento de biomassa seca, destacam-se a radiação solar, temperatura do ar e temperatura e umidade do solo. A temperatura do ar média observadas nos meses de maio a agosto (Figura 2), ficaram entre os 15 e $18{ }^{\circ} \mathrm{C}$, com mínimas observadas nos meses de maio de $9,9{ }^{\circ} \mathrm{C}$, em junho de $4,1{ }^{\circ} \mathrm{C}$, em julho de $0,3{ }^{\circ} \mathrm{C}$ e em agosto com $6,2{ }^{\circ} \mathrm{C}$, temperaturas essas inferiores a temperatura ótima para o crescimento da espécie que é de 25 a $40^{\circ} \mathrm{C}$, com mínima de aproximadamente $15^{\circ} \mathrm{C}$ (DALL'AGNOL et al., 2004).

Dentre as cultivares estudados o Carajás apresentou $0,220 \mathrm{~kg}$ de proteína bruta. $\mathrm{kg}^{-1} \mathrm{de}$ biomassa seca na fração folha, valor semelhante $(\mathrm{P}>0,05)$ aos $0,215 \mathrm{~kg}$ da cultivar BRS Kurumi, enquanto que a cultivar Cameron apresentou 0,190 kg de PB. $\mathrm{kg}^{-1}$ inferior $(\mathrm{P}<0,05)$ ao verificado na cultivar Carajás e semelhante $(\mathrm{P}<0,05)$ a cultivar BRS Kurumi.

Os valores médios observados de Proteína Bruta para as cultivares avaliados durante o período outono/inverno foram acima dos valores de 0,130 e $0,105 \mathrm{~kg}$ de $\mathrm{PB} \cdot \mathrm{kg}^{-1}$ de BMS observados por Tegani Neto e Mello (2007) na cultivar Paraiso, cortados aos 30 e 60 dias, e superiores aos 0,151 e 0,139 kg de PB. $\mathrm{kg}^{-1}$ de BMS observados por Meinerz et al. (2008) em Pennisetum purpureum Schum. cv. Merckeron Pinda em sistema com princípios agroecológicos e convencional, respectivamente, e das $0,173 \mathrm{~kg}$ de $\mathrm{PB} . \mathrm{kg}^{-1}$ de BMS relatados por Maranhão et al. (2018b) em Pennisetum purpureum Schum. cv. Roxa com 36 dias de idade. Na compilação de dados de alimentos para bovinos Valadares Filho et al. (2016) citam valores em cultivares de Pennisetum purpureum Schum. variando de 0,069 a 0,129 kg de PB. $\mathrm{kg}^{-1}$ de BMS, sendo variabilidade influenciada pelas cultivares, idade da planta, a composição do material se mais folha ou mais colmos.

Observando os resultados obtidos no presente estudo com os observados pelos autores; Tegani Neto e Mello (2007); Meinerz et al. (2008) e por Valadares Filho et al. (2016) e Maranhão et al. (2018b) as diferenças no conteúdo de proteína bruta está mais relacionada a utilização de diferentes cultivares, e a metodologia utilizada nas avaliações, onde foi deixado resíduo de 0,50 m, o que proporcionou maior acumulo de folhas em relação a caule, enquanto que nos trabalhos citados não fica evidenciado em que altura as avaliações foram realizadas. 
Conforme relataram Cecato et al. (2003), a MS disponível para bovinos em produção leiteira a pasto, a disponibilidade de proteína bruta deve ser superior a $12 \% \mathrm{~PB}$ ou $0,120 \mathrm{~kg}^{-1} \mathrm{de}^{\mathrm{d}}$ PB na BMS, além da boa produção de BMV, sendo que esses dois atributos foram bem representativos nas cultivares de Pennisetum purpureum Schum estudados no período outono/inverno, isso se torna importante pois na região onde foi realizado o estudo, nesse período ocorre a queda da produtividade das forrageiras perenes de verão dos gêneros (Cynodon, Pannicum e Brachiaria) e as principais forrageiras anuais de inverno cultivadas a Avena strigosa Schreb, a Avena sativa L. e o Lolium multuflorum L., estão sendo ainda introduzidas ou não apresentam condições de pastejo, ocasionando queda na produtividade dos rebanhos, principalmente do leiteiro que é a base da agricultura familiar da região.

Dentre as características de qualidade da pastagem além da proteína bruta, deve-se levar em consideração a participação na forragem da fibra digestível neutra (FDN) e da fibra digestível acida (FDA), frações que interferem na quantidade e na digestibilidade do alimento ingerido pelo animal. Para Cecato et al. (2003) a qualidade da pastagem reflete diretamente no desempenho animal que é melhorado pela maior ingestão de proteína e energia digestível. Quanto ao nível de ingestão de MS esse é influenciado pelo conteúdo de FDN presente na dieta ofertada a bovinos (DETMANN et al., 2006).

Na tabela 2 estão descritos a participação de fibra digestível neutra (FDN), fibra em detergente ácida (FDA) e de nutrientes digestíveis totais (NDT) na biomassa seca de Pennisetum purpureum Schum. cultivares Carajás, Cameron e Kurumi durante o período outono/inverno.

Tabela 1 - Fibra digestível neutra em kg (FDN), Fibra em detergente ácida em kg (FDA) e de Nutrientes digestíveis totais em kg (NDT) na biomassa seca de Pennisetum purpureum Schum. das cultivares Carajás, Cameron e BRS Kurumi durante o período outono/inverno.

\begin{tabular}{cccc}
\hline Cultivar & FDN, kg & FDA, kg & NDT, kg \\
\hline Carajás & $0,457^{\mathrm{b}}$ & $0,394^{\mathrm{a}}$ & $0,647^{\mathrm{a}}$ \\
Cameron & $0,566^{\mathrm{a}}$ & $0,356^{\mathrm{a}}$ & $0,602^{\mathrm{b}}$ \\
BRS Kurumi & $0,530^{\mathrm{a}}$ & $0,359^{\mathrm{a}}$ & $0,617^{\mathrm{b}}$ \\
\hline
\end{tabular}

Letras iguais nas colunas não diferem entre si pelo teste de Tukey a 5\%

O valor do FDN das cultivares de Pennisetum purpureum Schum. no período de outono/inverno estão classificados como de boa qualidade, apresentando valores de 0,457; 0,566 e $0,530 \mathrm{~kg}^{-1}$ de BMS das cultivares Carajás, Cameron e BRS Kurumi, respectivamente. Esses valores observados são inferiores aos 0,650 kg de FDN. $\mathrm{kg}^{-1}$ de BMS, considerado como limitante do consumo de forragem para bovinos (FREITAS et al., 2006). Em níveis altos de FDN a fração 
indigestível, a lignina, além de limitar o consumo, diminui a degradação da parede celular interferindo na capacidade fermentativa da digesta no rúmen e podendo quando em grande quantidade indisponibilizar a absorção de nutrientes nos intestinos. Compilando os dados de Pennisetum purpureum Schum. é observado que os valores relatados por Valadares Filho et al. (2016) para a FDN são muito superiores aos verificados no presente experimento, sendo que esses apresentaram variações de 62,90 até 76,25\% (0,629 até 0,762 kg de FDN. $\left.\mathrm{kg}^{-1} \mathrm{BMS}\right)$, sendo influenciada pela idade da forragem em que a avaliação foi realizada.

$\mathrm{Na}$ avaliação das cultivares é importante frisar que a metodologia adotada para estimar os conteúdos de PB, FDN e FDA, pode ter influenciado na composição desses nutrientes, onde os cortes foram realizados a $50 \mathrm{~cm}$ do solo, proporcionando no material analisado maior quantidade de folhas em relação ao caule, o que melhor quantidade nutricional, diminuindo o material insolúvel presente na FDN (celulose+hemicelulose+liguinina) e a FDA (celulose+liguinina+sílica) representada pela fração lignificada da planta.

A participação da FDA foi semelhante $(\mathrm{P}>0,05)$ entre as cultivares, apresentando valores médios de 0,394; 0,356 e 0,359 kg de FDA. $\mathrm{kg}^{-1}$ de BMS, para as cultivares Carajás, Cameron e BRS Kurumi, respectivamente. No presente estudo as plantas foram cortadas em intervalos de 30 dias, ocasionando semelhança na composição da FDA. Aumento na participação da FDA em Pennisetum purpureum Scum. manejados com intervalos de pastejo de 30 e 45 dias foram relatados por Deresz (1994), onde os valores verificados foram de $38,60 \%$ para $42,50 \%(0,380$ e $0,425 \mathrm{~kg}$ de FDA. $\mathrm{kg}^{-1}$ de BMS), respectivamente, demonstrando a importância do pastejo em plantas mais jovens onde a participação de folhas é maior que a de colmos, o que melhora a digestibilidade dos nutrientes presentes na folha.

A participação energética da dieta pode ser medida através do NDT que está inversamente relacionado a participação da FDN (CAPELLE et al., 2001). Os valores observados apresentaram diferença entre as cultivares estudados, onde o maior valor $(\mathrm{P}>0,05)$ observado para a cultivar Carajás $\left(0,647 \mathrm{~kg}\right.$ de NDT. $\mathrm{kg}^{-1}$ de BMS), enquanto que as cultivares Cameron e BRS Kurumi apresentaram valores semelhantes $(\mathrm{P}>0,05)$ de 0,602 e 0,617 $\mathrm{kg}$ de NDT.kg ${ }^{-1}$ de BMS, respectivamente. Os valores observados no presente estudo são superiores aos 48,97 a 52,67\% de NDT $\left(0,490\right.$ e 0,527 kg de NDT. $\mathrm{kg}^{-1}$ de BMS) relatados por Valadares Filho et al. (2016), diferenças atribuídas, provavelmente, ao espessamento e lignificação da parede celular vegetal com o avanço da idade da planta, principalmente, pelo aumento da proporção de colmos no material colhido.

Na tabela 3 estão descritos os conteúdos de minerais presentes nas cultivares estudados. Para ruminantes em pastejo, normalmente ocorre déficit na ingestão de minerais, principalmente 
o fósforo em pastagens tropicais (LANA, 2005) e é importante para o normal funcionamento de todos os processos biológicos corporais (PEDREIRA; BERCHIELLI, 2011), enquanto o potássio é encontrado em quantidades adequadas e em alguns momentos pode interferir negativamente na fisiologia do animal, tornando importante a determinação da composição dos minerais presentes nas forragens.

Tabela 2 - Analise do conteúdo dos minerais cálcio ( $\mathrm{Ca}, \mathrm{g})$, fósforo $(\mathrm{P}, \mathrm{g})$, Potássio (K ), magnésio $(\mathrm{Mg})$, Cobre $(\mathrm{Cu})$, ferro $(\mathrm{Fe})$ e zinco $(\mathrm{Zn})$ na biomassa seca das cultivares de Pennisetum purpureum Carajás, Cameron e BRS Kurumi durante o período outono/inverno.

\begin{tabular}{cccccccc}
\hline Cultivares & $\mathbf{C a}, \mathbf{g}$ & $\mathbf{P}, \mathbf{g}$ & $\mathbf{K}, \mathbf{g}$ & $\mathbf{M g}, \mathbf{g}$ & $\mathbf{C u}, \mathbf{m g}$ & $\mathbf{F e}, \mathbf{m g}$ & $\mathbf{Z n}, \mathbf{m g}$ \\
\hline Carajás & $5,63^{\mathrm{a}}$ & $6,30^{\mathrm{a}}$ & $30,0^{\mathrm{a}}$ & $2,80^{\mathrm{a}}$ & $10^{\mathrm{a}}$ & $173,25^{\mathrm{a}}$ & $370^{\mathrm{a}}$ \\
Cameron & $5,06^{\mathrm{a}}$ & $6,30^{\mathrm{a}}$ & $30,8^{\mathrm{a}}$ & $2,80^{\mathrm{a}}$ & $10^{\mathrm{a}}$ & $190,25^{\mathrm{a}}$ & $390^{\mathrm{a}}$ \\
BRS Kurumi & $4,85^{\mathrm{a}}$ & $5,90^{\mathrm{a}}$ & $27,1^{\mathrm{b}}$ & $2,60^{\mathrm{b}}$ & $10^{\mathrm{a}}$ & $208,75^{\mathrm{a}}$ & $380^{\mathrm{a}}$ \\
\hline Média & 5,18 & 6,17 & 29,30 & 2,70 & 10 & 190,75 & 380 \\
\hline
\end{tabular}

Letras iguais nas colunas não diferem entre si pelo teste de Tukey a 5\%

O National Research Council (2016), traz em suas tabelas de composição de alimentos, que o Pennisetum purpureum Schum. em estado vegetativo apresenta em sua composição 0,6\% na BMS (6 g. $\mathrm{kg}^{-1}$ na BMS) de cálcio, valor acima dos 5,18 g. $\mathrm{kg}^{-1}$ de BMS observados nas cultivares de Pennisetum purpureum Schum. estudados no presente trabalho. Na compilação dos dados disponibilizados por Valadares Filho et al. (2016) os valores verificados de cálcio apresentaram variação entre 0,34 a 0,57\% na BMS (3,4 a 5,7 g. $\mathrm{kg}^{-1}$ de BMS), já Maranhão et al. (2018b) relatam teores de 1,31g em Pennisetum purpureum Schum. Roxo com 30 dias de idade. Conforme relatado por Pedreira e Berchielli, (2011) a composição de cálcio na forragem tem influência da espécie estudada, da porção da planta, condição de fertilidade do solo, estado fisiológico da planta, além de influências diretas do clima (temperatura, insolação e pluviometria), sendo que o requerimento de cálcio pelo animal, varia com a idade e o estado fisiológico, apresentando amplitude de 0,20 a 0,60\% na BMS da ração ingerida pelo bovinos (LANA, 2005).

O fósforo para os ruminantes, tem importância significativa na atividade microbiana, como também em outros herbívoros e carnívoros está presente em todas as células corporais. É o mineral com maior número de funções conhecidas (PEDREIRA; BERCHIELLI, 2011). Em bovinos os requerimentos de fósforo apresentam grande amplitude, que segundo Lana (2005) começam com $0,12 \%$ da BMS quando na fase de crescimento até $0,41 \%$ da BMS em vacas lactantes. 
Os valores observados de fósforo nas cultivares de Pennisetum purpureum estudados foram semelhantes $(\mathrm{P}>0,05)$, com valor médio de 6,17 g. $\mathrm{kg}^{-1}$ BMS. Maranhão et al. (2018b) verificaram valores de $8,12 \mathrm{~g} . \mathrm{kg}^{-1}$ BMS, valores superiores aos 4,1 g. $\mathrm{kg}^{-1}$ de BMS, verificados no National Research Council (2016) e aos 1,8 a 2,8 g. $\mathrm{kg}^{-1}$ de BMS compilados por Valadares Filho et al. (2016).

Os valores superiores de participação de fósforo em relação aos disponibilizados na literatura, deve-se principalmente a adubação realizada no experimento, onde primeiramente foi realizada a análise de solo e disponibilizado os nutrientes, via adubação de NPK no plantio, necessários para o desenvolvimento adequado das cultivares de Pennisetum purpureum Schum. e também por se tratar de primeiro ano de cultivo, onde a disponibilidade de nutrientes no solo é mais alta para as plantas.

A mesma hipótese também serve para a participação do potássio nas cultivares de Pennisetum purpureum Schum., onde o BRS Kurumi foi o que apresentou menor $(\mathrm{P}<0,05)$ participação em relação as cultivares Carajás e Cameron que foram semelhantes $(\mathrm{P}>0,05)$, valores de 27,1; 30,0 e 30,8 g. $\mathrm{kg}^{-1}$ de BMS, acima dos 13,1 g. $\mathrm{kg}^{-1}$ de BMS relatados no National Research Council (2016) e das 15,9 até 25,9 g. $\mathrm{kg}^{-1}$ de BMS nos dados compilados de Valadares Filho et al. (2016). Porém Maranhão et al. (2018b) relatam valores de $\mathrm{K}$ de 123,66 g. $\mathrm{kg}^{-1} \mathrm{de}$ BMS, muito superiores aos verificados na literatura para cultivares de Pennisetum purpureum Schum. com 30 dias de idade.

A participação do potássio verificado nas cultivares de Pennisetum purpureum Schum. estudados, levanta um alerta, sobre a disponibilidade em excesso desse mineral nas pastagens, que quando aliado a níveis elevados de proteína, como observados na tabela 1, podem inibir a absorção do magnésio, principalmente em vacas de alta produção leiteira, causando distúrbios metabólicos como a hipomagnesemia que tem como consequências diretas no aumento nos índices de retenção de placenta, tetania e distúrbios ruminais. A disponibilidade do potássio nas forragens verdes está intimidante ligado a utilização adubação a base de NPK, o potássio é mineral essencial para o desenvolvimento das forragens, enquanto que o magnésio é um mineral que tem pouca influência no desenvolvimento foliar da forrageiras, mas que tendo aumento da participação quando a forragem passa pelo processo de desidratação e é transformada em feno.

A participação de magnésio verificada nas cultivares de Pennisetum purpureum Carajás, Cameron e BRS Kurumi, foram de 2,8; 2,8 e 2,6 g. $\mathrm{kg}^{-1}$ na BMS, onde a cultivar Kurumi apresentou menor $(\mathrm{P}<0,05)$ participação em relação aos demais cultivares. Conforme descrito no National Research Council (2016) a participação de magnésio Pennisetum purpureum Schum. é de 2,6 g. $\mathrm{kg}^{-1}$ na BMS, em quanto que por Valaderes Filho et al. (2016) em seu programa de 
nutrição de bovinos de corte a participação do magnésio na planta tem variação de $2,2 \mathrm{~g} \cdot \mathrm{kg}^{-1}$ até 4,2 g.kg-1 na BMS, enquanto que Maranhão et al. (2018b) observaram valores de 4,98 g.kg ${ }^{-1}$ na BMS, sendo o fator de variação cultivares e idades de plantas (Valadares Filho et al., 2016), corroborando com Pedreira e Berchielli (2011) que afirmam que a participação do magnésio na planta é dependente da espécie estudada, do estágio de crescimento, das condições ambientais e do teor de magnésio no solo.

Os valores de cobre observados foram semelhantes $(\mathrm{P}>0,05)$ entre as cultivares de Pennisetum purpureum Schum. com valor de $10 \mathrm{mg} \cdot \mathrm{kg}^{-1}$ de BMS. O cobre tem função em inúmeros processos fisiológicos principalmente como componente de enzimas (Pedreira e Berchielli, 2011). Nas forragens o seu valor é limitando, não atendendo as exigências dos ruminantes, sendo que seu valor tem como fonte de variação a espécie da planta e a disponibilidade no solo (PEDREIRA; BERCHIELLI, 2011).

O ferro é micromineral abundante nos solos brasileiros, o que ocasiona concentrações adequadas de ferro nas plantas atendendo as exigências dos animais, esse mineral atua metabolismo estando diretamente no transporte e utilização de oxigênio, como componente de proteína como a hemoglobina e a mioglobina (PEDREIRA; BERCHIELLI, 2011). Os valores de ferro verificados nas cultivares de Pennisetum purpureum Schum. forma semelhantes $(\mathrm{P}>0,05)$ com valor médio de 190,75 mg.kg-1 de BMS, Pedreira e Berchielli (2011) citam que as forrageiras apresentam valores que variam de 70 a $500 \mathrm{mg}$ de Fe. $\mathrm{kg}^{-1}$.

O zinco apresentou valor médio de $380 \mathrm{mg} / \mathrm{kg}^{-1}$ de BMS, entre as cultivares de Pennisetum purpureum Schum., é considerado mineral relacionado a imunidade dos animais, sendo que sua deficiência pode causar mortalidade, através da diminuição de linfócitos no sangue (PEDREIRA; BERCHIELLI, 2011).

\section{CONCLUSÃO}

A maior produção de biomassa verde foi verificada nas cultivares de Pennsetum Purpureum Cameron, seguido do BRS Kurumi. Na biomassa seca o cultivar BRS Kurumi apresentou melhor produção seguido pelo Cameron enquanto o cultivar Carajás apresentou a menor produção de biomassa seca. A maior participação de proteína bruta foi verificada no cultivar Carajás seguida do Kurumi que se assemelhou ao do Cameron. A FDN e o NDT apresentaram melhores valores na cultivar Carajás, enquanto que a FDA foi semelhante entre as cultivares. A participação dos minerais Cálcio, Fósforo, Cobre, Ferro e Zinco foram semelhantes nas cultivares estudados, enquanto que os minerais Potássio e Manganês 
apresentaram menores valores no cultivar BRS Kurumi.

\section{REFERENCIAS}

ABIEC - Associação Brasileira das Indústrias Exportadoras de Carnes. 2018. Beff report Perfil da pecuária no Brasil Disponível em :

〈http://www.abiec.com.br/controle/uploads/arquivos/sumario2019portugues.pdf $>$

CAPPELLE, E. D. et al . Estimativas do Valor Energético a partir de Características Químicas e Bromatológicas dos Alimentos. Revista Brasileira de Zootecnia, Viçosa, v. 30, n. 6, p. 1837 1856, dez. 2001. Disponível em <http://www.scielo.br/scielo.php?script=sci_arttext\&pid=S1516$35982001000700022 \& \operatorname{lng}=$ pt\&nrm=iso $>$. acessos em 10 jun. 2018.

http://dx.doi.org/10.1590/S1516-35982001000700022.

CARVALHO, C. A. B. et al. 2000. Efeitos da fertilização de cobertura e do intervalo entre cortes sobre a produção e o valor nutritivo do capim-elefante. Ciência Agrotécnologia, n.24, v.1, p. 233-241, 2000.

CECATO, U. et al. Pastagens para a produção de leite. Boletim técnico, 2003. Disponível em: http://www.nupel.uem.br/pos-ppz/pastagens-08-03.pdf

CIRAM. Centro de Informações de Recursos Ambientais e de Hidrometeorologia de Santa Catarina. EPAGRI/CIRAM. 2017. Disponível em: <http://ciram.epagri.sc.gov.br/>

CONAB. Companhia Nacional de Abstecimento. 2017 .Conjuntura mensal especial, leite e derivados. Abr. 2018. Disponível em:

<https://www.conab.gov.br/busca?searchword=leite\&searchphrase=all >

DALL'AGNOL, M. et al. Produção de forragem de capim-elefante sob clima frio: curva de crescimento e valor nutritivo. Revista Brasileira de Zootecnia, Viçosa, v. 33, n. 5, p. 11101117, out. 2004 . Disponível em <http://www.scielo.br/scielo.php?script=sci_arttext\&pid=S1516$35982004000500002 \& \operatorname{lng}=$ pt\&nrm=iso $>$. acessos em 05 fev. 2018.

http://dx.doi.org/10.1590/S1516-35982004000500002.

DALFOVO, V.C. et al. Utilização de espécies forrageiras na bovinocultura leiteira da região sudoeste do paraná. In: CONGRESSO DE CIÊNCIA E TECNOLOGIA DA UTFPR - CÂMPUS DOIS VIZINHOS, 1; SEMINÁRIO: SISTEMAS DE PRODUÇÃO AGROPECUÁRIA, 5; SIMPÓSIO DE CIÊNCIAS FLORESTAIS E BIOLÓGICAS, 1. Dois Vizinhos, PR. Anais[...] Dois Vizinhos: editora UFTPR. p.398-402, 2011. Disponível em:

http://revistas.utfpr.edu.br/dv/index.php/CCT_DV/article/viewFile/650/408. Acesso em: 10 maio 2019.

DERESZ, F. Manejo de pastagens de capim-elefante para produção de leite e carne. In: SIMPÓSIO SOBRE CAPIM-ELEFANTE, 2. Juiz de Fora. Anais[...] Coronel Pacheco: editora. p.116-137. 1994. 
DETMANN, E. et al . Digestibilidade dos compostos nitrogenados insolúveis em detergente ácido em bovinos manejados em pastagem de capim-braquiária. Revista Brasileira de Zootecnia, Viçosa, v. 35, n. 4, p. 1463-1468, ago. 2006 . Disponível em $<$ http://www.scielo.br/scielo.php?script=sci_arttext\&pid=S151635982006000500028\&lng=pt\&n rm=iso>. acessos em 08 jun. 2018. http://dx.doi.org/10.1590/S1516-35982006000500028.

EMBRAPA - Empresa Brasileira de Pesquisa Agropecuária - Centro Nacional de Pesquisa de Solos. 2013. Sistema Brasileiro de Classificação de Solos. (3nd ed.) Rio de Janeiro, RJ. 353 p.

FREITAS, A. W. de P. et al . Avaliação da qualidade nutricional da silagem de cana-de-açúcar com aditivos microbianos e enriquecida com resíduo da colheita de soja. Revista Brasileira de Zootecnia, Viçosa, v. 35, n. 1, p. 38-47, fev. 2006 . Disponível em <http://www.scielo.br/scielo.php?script=sci_arttext\&pid=S151635982006000100005\&lng=pt\&n rm=iso>. acessos em 09 jun. 2018 http://dx.doi.org/10.1590/S1516-35982006000100005.

INMET. INSTITUTO NACIONAL DE METEOROLOGIA. Normais climatológicas do Brasil 1961-1990. 2018. Disponível em:

<http://www.inmet.gov.br/portal/index.php?r=clima/normaisClimatologicas

IBGE - INSTITUTO BRASILEIRO DE GEOGRÁFIA E ESTATÍSTICA - disponível em: https://brasilemsintese.ibge.gov.br/agropecuaria/utilizacao-das-terras-area.html. Acesso em: 11 de abr. 2019.

LANA, R. de P. Nutrição e alimentação animal (mitos e realidades). 2.Ed. Viçosa. UFV. 344 p. 2005.

MALAVOLTA, E. et al.. Avaliação do estado nutricional das plantas: princípios e aplicações. 2. Ed. Piracicaba: POTAFOS. 319 p.1997.

MARANHÃO, T.D. et al. Biomass components of Pennisetum purpureum cv. Roxo managed at different growth ages and seasons. Revista Brasileira de Saúde e Produção Animal, Salvador, v. 19, n. 1, p. 11-22, mar. 2018a. Disponível em

<http://www.scielo.br/scielo.php?script=sci_arttext\&pid=S151999402018000100011\&lng=pt\&n rm=iso> . acessos em 02 jan. 2019. http://dx.doi.org/10.1590/s1519-99402018000100002.

MARANHÃO, T.D. et al. Accumulation and partition of macronutrients in Pennisetum purpureum cv. Roxo managed under different growth ages and seasons. Revista Brasileira de Saúde e Produção Animal, Salvador, v.19, n.3, p.223-240, set. 2018b. Disponível em <http://www.scielo.br/scielo.php?script=sci_arttext\&pid=S151999402018000300223\&lng=pt\&n rm=iso>. acessos em 12 abr. 2019. http://dx.doi.org/10.1590/s1519-99402018000300001.

MEINERZ, G. R. et al. Composição nutricional de pastagens de capim-elefante submetido a duas estratégias de manejo em pastejo. Acta Scientiarum Animal Science, Maringá, v. 30, n. 4, p. 379-385, 2008. Disponível em < http://dx.doi.org/10.4025/actascianimsci.v30i4.3476> acessos em 10 abr. 2018.

NRC - NATIONAL ACADEMIES OF SCIENCES, ENGINEERING, AND MEDICINE. 2016. Nutrient Requirements of Beef Cattle: Eighth Revised Edition. Washington, DC: The National Academies Press. https://doi.org/10.17226/19014. 
PEDREIRA, M. DOS S.; BERCHIELLI, T.T. 2011. Minerais. In: Nutrição de Ruminantes, $2^{\circ}$ Ed. Editores: Berchielli; Pires, A.V. Oliveira, S.G. de. Jaboticabal, FUNEP. 616p.

SENGER, C. C. D. et al. Evaluation of autoclave procedures for fiber analysis in forage and concentrate feedstuffs. Animal Feed Science and Technology, 146, p. 169-174. 2008. http://dx.doi.org/10.1016/j.anifeedsci.2007.12.008

SILVA, D. J.; QUEIROZ, A. C. Análise de alimentos: métodos químicos e biológicos. 2006. 3. ed. Viçosa: UFV. 235p.

TEGAMI NETO, A.; MELLO, S. P. Avaliação da produtividade e qualidade do capim elefante paraíso (Pennisetum hybridum), em função de diferentes doses de nitrogênio em cobertura e frequência de corte. Nucleus, v. 4, n.1, p. 9-12. 2007.http://dx.doi.org/10.3738/nucleus.v4i1.4

VALADARES FILHO, S.C. et al. BR-CORTE 3.0. Cálculo de exigências nutricionais, formulação de dietas e predição de desempenho de zebuínos puros e cruzados. 2016. Disponível em www.brcorte.com.br.

VIANA, B.L. et al. Morphological characteristics and proportion of leaf blade tissues of elephant grass clones under sheep grazing Pesquisa Agropecuária Brasileira, Brasília , v. 53, n. 11, p. 1268-1275, nov. 2018. Disponível em <http://www.scielo.br/scielo.php?script=sci_arttext\&pid=S0100204X2018001101268\&lng=pt\&nrm=iso > . acessos em 10 abr. 2019. http://dx.doi.org/10.1590/s0100-204x2018001100009. 